\title{
La influencia de la experiencia en el modelamiento de las representaciones sociales sobre la relación familia-escuela en establecimientos educacionales rurales de la región de Ñuble, Chile
}

\author{
The Influence of Experience in the Modeling of Social Representations of the Family-School \\ Relationship in Rural Educational Institutions in the Nuble Region, Chile
}

\section{A influência da experiência na modelagem das representações sociais sobre a relação família-escola em estabelecimentos de ensino rural na região Ñuble, Chile}

Héctor Cárcamo-Vásquez

Universidad del Bío Bío

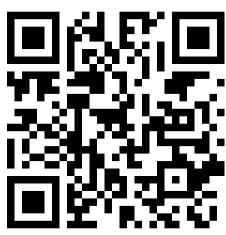

Chillán, Chile

hcarcamo@ubiobio.c

https://orcid.org/0000-0003-2045-343X

Pablo Méndez-Bustos

Universidad Católica del Maule

Talca, Chile

pmendez@ucm.cl

https://orcid.org/0000-0002-9026-6974

\author{
Recibido • Received • Recebido: 13 / 10 / 2017 \\ Corregido • Revised • Revisado: 03 / 12 / 2018 \\ Aceptado • Accepted • Aprovado: 17 / 04 / 2019
}

\begin{abstract}
Resumen: El trabajo presenta la influencia que tiene la experiencia de los agentes en el modelamiento de la representación que poseen sobre la relación familia-escuela en contexto rural. El objetivo del estudio es reconocer las representaciones sociales que profesorado y familias poseen respecto a la relación familiaescuela. La metodología utilizada corresponde a la cualitativa a través del método sociofenomenológico, la técnica de producción de datos es la entrevista semiestructurada. La investigación se desarrolla en 10 escuelas rurales pertenecientes a la Región de Ñuble en Chile. Se entrevistó a un total de 16 docentes y 36 personas apoderadas; los datos se analizaron mediante el análisis semántico. Los resultados muestran que la experiencia vital de los sujetos agentes influye en la representación que poseen sobre la relación familiaescuela y el papel que a cada sujeto agente involucrado le atribuye. Desde el profesorado, se aprecia una distinción entre las concepciones derivadas de la experiencia docente, experiencias personales y el conocimiento acabado del contexto. Por su parte, las familias reconocen la influencia de la experiencia derivada del ciclo vital familiar, diferenciando entre personas apoderadas primerizas y aquellas que inclusive se responsabilizan por el cuidado de nietos y nietas. A modo de conclusión, la influencia de la experiencia como modeladora de las representaciones que profesorado y familias poseen respecto de la relación familia-escuela y el rol que a cada sujeto le compete está dada por la confluencia de los múltiples mundos vividos por los sujetos agentes interpelados.
\end{abstract}

Palabras claves: Familia; escuela; agentes; experiencia; ruralidad. 
doi: http://dx.doi.org/10.15359/ree.23-3.4

URL: http://www.una.ac.cr/educare

CORREO: educare@una.cr

\begin{abstract}
This work presents the influence of agents' experience in modeling the representation they have of the family-school relationship in the rural context. The objective of the study is to recognize the social representations that teachers and families have regarding the family-school relationship. The methodology used corresponds to the qualitative design through the case study method; the data processing technique is the semi-structured interview. The research was conducted in 10 rural schools belonging to the Ñuble Region, Chile. A total of 16 teachers and 36 parents were interviewed, and the data was analyzed through semantic analysis. The results showed that the life experience of the agents influences the representation they have about the family-school relationship and the role each agent involved attributes to it. From the teaching staff, a distinction can be seen between the conceptions derived from the teaching experience, personal experiences, and the complete knowledge of the context. For their part, families recognize the influence of experience derived from the family life cycle, differentiating between first-time parents and those who are even responsible for the care of grandchildren. In conclusion, the influence of experience, as a modeler of the representations that teachers and families have regarding the family-school relationship and the role each subject has, comes from the confluence of the multiple experiences lived by the agents interviewed.
\end{abstract}

Keywords: family-school relationship; agents; experience; rural context.

Resumo: O trabalho apresenta a influência contida na experiência dos agentes na modelagem da representação que possuem sobre a relação família-escola no contexto rural. O objetivo do estudo é reconhecer as representações sociais que professores e famílias possuem sobre à relação famíliaescola. A metodologia utilizada corresponde à qualitativa através do método sociofenomenológico, a técnica de produção de dados é a entrevista semiestruturada. A pesquisa é realizada em 10 escolas rurais pertencentes à região Ñuble, no Chile. Um total de 16 professores e 36 pessoas apoderadas foram entrevistados; os dados foram analisados por análise semântica. Os resultados mostram que a experiência de vida dos sujeitos agentes provoca influência na representação que eles têm sobre a relação famíliaescola e o papel que cada sujeito agente participante lhe atribui. Do corpo docente, há uma distinção entre as concepções derivadas da experiência docente, as experiências pessoais e o conhecimento acabado do contexto. Por sua vez, as famílias reconhecem a influência da experiência derivada do ciclo de vida familiar, diferenciando as pessoas apoderadas pela primeira vez e as que são responsáveis pelo cuidado dos netos e netas. A título de conclusão, a influência da experiência como modeladora das representações que professores e famílias possuem sobre a relação família-escola e o papel que cada sujeito possui é dada pela confluência dos múltiplos mundos vividos pelos sujeitos agentes interpelados.

Palavras-chave: Família; escola; agentes; experiência; mundo rural.

\title{
Introducción
}

El artículo que se presenta está estructurado de la forma que a continuación se indica. En este primer apartado exponemos los aspectos teóricos y conceptuales que sirven de marco interpretativo para los datos producidos; en un segundo momento presentamos los elementos relativos al contexto en el cual se desarrolla la investigación; en tercer lugar, se dan a conocer las técnicas y métodos escogidos para abordar el estudio; en cuarto lugar, compartimos los resultados más relevantes como consecuencia del análisis del corpus discursivo y, finalmente, dedicamos un apartado para las conclusiones. Antes de dar paso al desarrollo del presente trabajo, cabe señalar que el objetivo que se persigue en la investigación y en este trabajo en

\footnotetext{
2 Héctor Cárcamo-Vásquez y Pablo Méndez-Bustos

Los artículos de la Revista Electrónica Educare del Centro de Investigación y Docencia en Educación de la Universidad Nacional, Costa Rica, se comparten bajo términos de la Licencia Creative Commons: Reconocimiento, № Comercial, Sin Obra Derivada 3.0 Costa Rica. Las autorizaciones adicionales a las aquí delimitadas se pueden obtener en el correo: educare@una.cr
} 
particular es reconocer las representaciones sociales que profesorado y familias de escuelas rurales de la región de Ñuble, Chile, poseen respecto a la relación familia-escuela.

En la actualidad, uno de los temas de mayor interés en el contexto educativo formal corresponde a la relación familia-escuela. Diversos autores y autoras han estudiado la influencia de una adecuada relación entre las familias y el profesorado para el éxito escolar de los niños y las niñas, tal es el caso de Páez (2015); asimismo Colás y Contreras (2013) analizaron los niveles de participación de las familias en el contexto escolar. Por otra parte, el papel de la relación familiaescuela para el desarrollo de escuelas inclusivas (Calvo, Verdugo y Amor, 2016); el modelo de aprendizaje dialógico (Chinchilla y Jiménez, 2015); los procesos comunicativos presentes en el marco relacional (Schilling, 2015) han sido otros procesos estudiados.

La mayoría de los estudios señalados se han realizado en contextos de vulnerabilidad social urbana y pocos son los análisis que incluyen estudios en contextos rurales (Vera, Osses y Schiefelbein, 2012). La nueva ruralidad requiere ser estudiada asumiendo sus particulares necesidades y requerimientos (Fawaz, 2015; Ramírez-Miranda, 2014). Esta nueva ruralidad responde a los cambios propios de lo social a partir de una articulación explícita de múltiples dimensiones, la medioambiental, la educacional, la productiva y la económica. La explicitación de la multidimensionalidad constitutiva de lo rural pone en evidencia la necesidad de remirarlo y, por tanto, reajustar las formas de abordaje teórico y conceptual.

Así, el presente trabajo analiza la influencia de la experiencia de los sujetos agentes en el modelamiento de la representación que tanto profesorado como familias poseen de la relación familia-escuela, en escuelas rurales de tres comunas de la región de Ñuble en Chile.

Pesquisar el contenido de las representaciones que poseen profesorado y familias, respecto de la relación que establecen en el contexto escolar, es de gran relevancia, si asumimos que dicha representación corresponde a diversos sistemas de creencias, prenociones y actitudes que los sujetos agentes configuran respecto a lo que acontece en su mundo. La representación social deriva del conocimiento popular. Pero no todo conocimiento popular, en palabras de Lacolla (2015, p. 23) “[el conocimiento popular] adquiere la categoría de representación cuando se reconoce en él la función de comunicación y elaboración de comportamiento entre los individuos". De acuerdo con Moscovici (1979), las representaciones sirven para orientar nuestras percepciones para actuar en el mundo en situaciones específicas; en consecuencia, se constituyen en marcos interpretativos de la realidad que intervienen en la forma de llevar a cabo nuestras acciones (Abric, 2001; Cuevas 2012). En consecuencia, siguiendo lo planteado por CárcamoVásquez (2015), las representaciones cumplen diversas funciones, entre las que cabe destacar las siguientes: 1) comprender el contexto en el que están situados los sujetos agentes, 2) permitir elaborar valoraciones respecto de diversos objetos de representación, 3) facilitar los procesos de comunicación entre los sujetos agentes y, 4) orientar nuestro modo de actuar. Siguiendo a Jodelet (1986, p. 474), las representaciones sociales son "modalidades de pensamiento práctico orientados hacia la comunicación, la comprensión y el dominio del entorno". 
doi: http://dx.doi.org/10.15359/ree.23-3.4

URL: http://www.una.ac.cr/educare

CORREO: educare@una.cr

Sobre la base de lo expuesto en el párrafo precedente, no cabe duda de que la experiencia vivida por los sujetos agentes cobre especial relevancia al momento de abordar las representaciones sociales. Pero, ¿por qué prestar atención a la experiencia de agentes? Una de las teorías clásicas desarrollada por Bourdieu y Passeron (1979) en su obra La reproducción. Elementos para una teoría del sistema de enseñanza. Enfatiza el papel que juega la escuela en los mecanismos de reproducción de la desigualdad social a través de la violencia simbólica presente en el proceso de enseñanza desde el advenimiento de la modernidad, lo que supuso un marco interpretativo de gran utilidad, como lo demuestra el trabajo desarrollado por Muñoz, Ajagan, Sáez, Cea y Luengo (2013). Sin embargo, hoy, hemos comenzado a transitar desde una concepción de escuela como agente de reproducción cultural a otra que la concibe como productora de cultura. En tal sentido, el trabajo desarrollado por Dubet (2010) respecto de la sociología de la experiencia abre nuevos horizontes para atender la escuela. A este respecto, cabe señalar:

La experiencia social se forma allí donde la representación clásica de 'la sociedad' no es ya adecuada, allí donde los actores están obligados a administrar simultáneamente varias lógicas de la acción, que remiten a diversas lógicas del sistema social, que ya no es entonces "un" sistema social, sino la copresencia de sistemas estructurados por principios autónomos. (p. 85)

En tal sentido, lo que acontece hoy en las escuelas rurales no responde a un conjunto de conductas sociales que se expresan en la cotidianeidad a partir de diversos códigos interiorizados y activados de forma automática producto de la socialización de sus agentes. Para comprender los procesos involucrados se requiere del reconocimiento de la experiencia de agentes no anclada en un centro gravitacional único; el análisis ha de incluir procesos afectivos y cognitivos fundamentales de esta experiencia. A pesar de reconocer la incompletitud de la experiencia social de agentes, en este caso profesorado y familias, se necesita acceder a ella tal como señala Dubet (2010, p. 87) "no hay una adecuación absoluta entre la subjetividad del actor y la objetividad del sistema". Precisamente, en esta idea radica el interés por utilizar este marco interpretativo y así acceder a las representaciones sociales que profesores y familias poseen respecto a la relación familia-escuela. Estas representaciones constituyen la experiencia vivida en multiplicidad de momentos y contextos y la articulación de elementos identitarios y de la acción propia de los sujetos agentes (Cárcamo-Vásquez, 2016).

\section{Elementos del contexto}

El estudio se desarrolla en tres comunas pertenecientes a la región de Ñuble cuya actividad económica predominante es la agricultura y la silvicultura con una población principalmente rural y una gran heterogeneidad territorial caracterizadas por zonas de secano interior, zona de montaña y valle central, donde se concentra el mayor número de población, especialmente urbana. La región está constituida por un total de 21 comunas distribuidas en tres territorios. Territorio de Secano constituido por las comunas de Cobquecura, Coelemu, Ninhue, Portezuelo, 
Quillón, Quirihue, Ranquil, San Nicolás y Trehuaco. Territorio Laja-Diguillín, compuesto por las comunas de Bulnes, Chillán Viejo, El Carmen, Pemuco, Pinto, San Ignacio y Yungay. Finalmente, el Territorio Punilla, al que pertenecen las comunas de Coihueco, Ñiquén, San Carlos y San Fabián.

Las escuelas estudiadas están situadas en tres comunas, una por cada territorio mencionado, correspondientes a microcentros de escuelas rurales en las comunas de Coihueco, Pemuco y Quillón.

Las escuelas seleccionadas presentan importantes diferencias en el número de matrículas efectivas por año y el número de docentes. De este modo, cabe consignar la existencia de escuelas unidocentes cuyas matrículas fluctúan entre 3 y 9 estudiantes, y escuelas polidocentes, cuya matrícula máxima alcanza 36 estudiantes al momento del trabajo de campo.

\section{Métodos y técnicas}

El diseño metodológico utilizado es cualitativo basado en el paradigma comprensivo interpretativo. El método corresponde a la sociofenomenología, dirigido al modelamiento de la representación respecto de la relación familia-escuela que cada agente posee.

Para la recogida de información se utilizaron entrevistas semiestructuradas. En los espacios de interlocución mediados por esta técnica se focaliza la atención en objetos de interés que permite, a los sujetos entrevistados, echar mano a recursos tales como: evocación, comparación, metáforas (Jodelet 1986). Dichos recursos facilitan el acceso -en el plano de lo enunciado- a los contenidos, fuentes y agentes que configuran las representaciones. Por ello, en esta investigación se generaron espacios dialógicos a partir de los cuales los sujetos agentes compartieron con su interlocutor o interlocutora la visión que tiene de la relación familia-escuela, para -a partir de ese contexto específico de enunciación- analizar el peso de la experiencia como fuente de configuración de la representación.

Para estos efectos se elaboraron dos guiones de entrevista, los cuales se validaron a partir de la aplicación de entrevistas piloto (una por cada tipo de agente). Los instrumentos se componen de cuatro bloques temáticos: antecedentes generales, contenidos de representación, fuentes que originan la representación y, por último, agentes que intervienen en la configuración de la representación. Los instrumentos fueron sometidos a validación por juicio experto. Siguiendo los planteamientos de Dubet (2010), durante el proceso de interlocución se invitó a las personas entrevistadas a distanciarse de sí, constituyéndose en sujetos que miran críticamente su experiencia.

Se entrevistó un total de 36 personas apoderadas', como representantes de las familias de los niños y las niñas y 16 docentes. La distribución del grupo de informantes se describe en la Tabla 1.

\footnotetext{
${ }^{1}$ Apoderada corresponde a la persona adulta que asume la responsabilidad de representación del niño o niña ante la escuela. Habitualmente este papel es desempeñado por la madre, el padre u otro familiar cercano al niño o niña; en el caso de esta investigación algunas personas entrevistadas correspondían a las abuelas.
} 
doi: http://dx.doi.org/10.15359/ree.23-3.4

URL: http://www.una.ac.cr/educare

CORREO: educare@una.cr

Tabla 1: Sujetos informantes. Según tipo de informante y comuna

\begin{tabular}{lccc}
\hline \multirow{2}{*}{ Comuna } & \multicolumn{2}{c}{ Tipo de informante } & \multirow{2}{*}{ Total } \\
\cline { 2 - 3 } & Familia & Profesorado & \\
\hline Coihueco & 7 & 4 & 11 \\
Quillón & 16 & 8 & 24 \\
Pemuco & 13 & 4 & 17 \\
\hline Total & 36 & 16 & $\mathbf{5 2}$ \\
\hline
\end{tabular}

Nota: Elaboración propia.

Respecto a los criterios de selección de los sujetos, cabe señalar que, para el caso de docentes, se entrevistó a la totalidad del profesorado que trabaja con modalidad de jornada completa en las escuelas estudiadas. En el caso de las personas apoderadas, se entrevistó a sujetos que manifestaran su disposición a participar del estudio (accesibilidad); asimismo se procuró asegurar la variabilidad estructural de la población atendiendo la edad de los sujetos y experiencia como persona apoderada (primeriza, experimentada).

Las escuelas que formaron parte del estudio en cada comuna corresponden a establecimientos educacionales que integran microcentros rurales. En el caso de la comuna de Quillón se pudo acceder a las tres escuelas que integran el microcentro de dicha comuna; para el caso de Coihueco, donde funcionan dos microcentros, se trabajó con uno de ellos accediendo solo a 3 de los 5 establecimientos que lo conforman. En el caso de la comuna de Pemuco, se trabajó con el único microcentro y se incluyeron 4 de un total de 7 establecimientos. Tanto en el caso de las escuelas de Coihueco como Pemuco, el número de escuelas estuvo condicionado por su disposición e interés en participar del proceso de investigación. Cabe consignar que la selección de las comunas obedece a dos criterios fundamentales: el primero, accesibilidad a la institucionalidad educacional local (Departamento de Administración de Educación Municipal, DAEM) y, como segundo criterio, el ser representativas de cada una de las provincias que constituyen la región de Ñuble.

El acceso a los sujetos agentes se logró a través de la identificación de informantes clave en cada una de las comunas; quienes orientaron el proceso de acceso al campo y sujetos a entrevistar. Dicho proceso se rigió por los criterios éticos vigentes para las ciencias sociales en la comunidad internacional. En tal sentido, se asegura la confidencialidad en el uso de la información, el resguardo de la identidad de los sujetos entrevistados utilizando pseudónimos en el material aquí referenciado. Asimismo, se aplicaron consentimientos informados debidamente visados por el Comité de Bioética y Bioseguridad de la Universidad del Bío-Bío. 
El análisis del corpus discursivo se realizó a partir de la técnica semántica estructural, desde el cual se desarrolló el proceso de codificación de los discursos con el fin de reconocer los significados que los sujetos otorgan a diversos objetos de atención. Una vez reconocidos estos elementos categoriales se establecieron mallas de sentido a través de la articulación de ejes semánticos para facilitar el acceso al flujo de significaciones presentes en el contexto de investigación. La estrategia de análisis se desarrolló combinando las estrategias de análisis transversal (entrevista por entrevista) y la longitudinal (de tipo temático). La combinación de las estrategias señaladas permite visualizar elementos constitutivos de la regularidad discursiva dentro del corpus, así como también los elementos propios de la variabilidad discursiva presente entre los sujetos agentes entrevistados.

Las categorías analizadas son de naturaleza deductiva. Las categorías fundamentales sobre las cuales se centró el análisis del corpus discursivo son (ver Tabla 2):

Tabla 2: Categorías deductivas para el análisis del corpus discursivo

\begin{tabular}{ll}
\hline \multicolumn{1}{c}{ Categoría } & \multicolumn{1}{c}{ Definición } \\
\hline Contenido de representación & $\begin{array}{l}\text { Referido a los elementos conceptuales de naturaleza abstracta que } \\
\text { permiten delimitar el cuerpo de la representación. }\end{array}$ \\
Fuente de representación & Referido al origen de la representación (relato, vivencias, normatividad). \\
$\begin{array}{l}\text { Agente que interviene en el } \\
\text { modelamiento de la representación }\end{array}$ & $\begin{array}{l}\text { Referido a personas o instituciones que intervienen en la configuración } \\
\text { de la representación. }\end{array}$ \\
\hline
\end{tabular}

Nota: Elaboración propia.

\section{Presentación y discusión de resultados}

Los resultados que se exponen en este apartado corresponden a las representaciones sociales que sobre la relación familia-escuela poseen tanto docentes como familias de las escuelas estudiadas. Se presentarán de forma separada la discusión de resultados en función del tipo de informante.

\section{Representaciones sociales sobre la relación familia-escuela desde la visión del profesorado}

La forma de significar y representar la relación familia-escuela, así como los roles que el profesorado asigna a las familias en esta correspondencia está mediada por las experiencias vividas como agentes. Una tendencia reconocida por el profesorado entrevistado plantea la relación con los cambios experimentados por las familias respecto del compromiso adoptado con el proceso formativo del estudiantado; compromiso factible de ser evaluado sobre la base de la comparación que solo la experiencia permite abordar. 
doi: http://dx.doi.org/10.15359/ree.23-3.4

URL: http://www.una.ac.cr/educare

CORREO: educare@una.cr

Desde el eje temporal dado por la experiencia profesional, reconocen que las familias actuales, a diferencia de las familias de antaño, muestran menos compromiso. A este respecto Roberto, profesor de la escuela más distante del casco urbano de la comuna estudiada sostiene lo siguiente:

La gente es como un poco apática ahora con la escuela. Están cambiados los apoderados. Se nota en el desinterés, porque los niños o los apoderados ahora como le digo, están en otra ellos. A ellos les interesa ganar plata, trabajar y que le cuiden al niño en la escuela ... hay varios apoderados de esos. Otros apoderados no están ni ahí con los chiquillos, por ejemplo, hay un niño que está en $8^{\circ}$ el más grandecito que estaba con la profesora, ese viene cuando a él se le antoja venir a la escuela y los papás no están nunca. (Roberto, profesor comuna de Coihueco)

Por otra parte, en el caso de Carmen, profesora con más de 30 años de carrera docente, señala que el profesorado deben enfrentar un problema común, el cual se relaciona con la falta de apoyo proporcionada por las familias:

La experiencia a uno le ayuda harto, mire nosotros también hablamos de eso y sabe uno de los grandes problemas que nosotros tenemos con los colegas y que coinciden, es que tenemos poco apoyo de los padres. Como que no está el compromiso de antes de que al niño en la casa le ayuden a hacer sus tareas, a estudiar, a prepararse para una prueba, uno se da cuenta por no vienen a las reuniones. (Carmen, profesora comuna de Pemuco)

En el relato de Carmen se pone de manifiesto que la representación familia-escuela está marcada desde la experiencia del profesorado sobre la base de lo que la escuela define como trascendental, no importando si corresponden a las familias de ayer o de hoy. Este elemento puede ser consignado como configurador del núcleo de la representación que el profesorado tiene de la relación familia-escuela. Cuando se plantea la falta de apoyo percibida -coincidentemente- por colegas en las reuniones de microcentro, se sitúa en relación al rol parental educativo que asignan a las familias: ayudar en casa. ¿Cuál es la ayuda requerida?, ¿qué se espera de las familias?, ¿qué se espera de los padres?, una ayuda para la realización de tareas de naturaleza escolar, asistir a reuniones de personas apoderadas y generar hábitos de estudio, como elementos más representativos (Cárcamo-Vásquez y Rodríguez-Garcés, 2015).

En una línea similar, María sostiene:

Es claro que hay algunos apoderados que lo único que esperan es que llegue el furgón para llevarse a los niños a la escuela en la mañana y luego que los regrese a las 16:30 y ni trabaja, tampoco va a reunión. Eso es algo que se nota, además una es mamá también y sabe, se da cuenta. Es que ni siquiera es que se tengan que preocupar del material, es que todo se los damos, todo se les entrega gratis. Carpetas con los nombres, compás, reglas, todo, es que todo se les entrega, pero igual no están. (María, profesora comuna de Quillón) 
María, al igual que Carmen, dan cuenta de la falta de compromiso que perciben por parte de los padres y madres, ambas aluden a su experiencia docente para referir a ello, identificando un eje de significación sobre la base de la presencia-ausencia. De acuerdo con sus discursos, se comprometen quienes asisten a las reuniones, a diferencia de aquellas familias que permanentemente se ausentan. A pesar de la coincidencia, a partir del relato de estas profesoras, en el caso de María, lo vincula a su experiencia como madre. Desde allí establece la valoración respecto al grado de compromiso por parte de las familias cuyos hijos o hijas asisten a la escuela en la cual se desempeña profesionalmente: "una es mamá también y sabe, se da cuenta". Como profesora y madre, María utiliza recursos argumentativos basados en la evaluación del compromiso de las familias; recursos que se desarrollan sobre la base de la experiencia vivida en contextos ajenos al desempeño profesional (Lahire, 2004).

Por otra parte, no todo se focaliza en una mirada desmejorada del rol parental. A pesar de ser referenciado regularmente en el corpus discursivo, este argumento tiende a relativizarse según se avanza en el proceso de interlocución. El profesorado también valora el compromiso de aquellas familias que conforman las directivas de las personas apoderadas. Estas son consideradas como un apoyo significativo, no para el quehacer mismo del profesorado, pero sí para la escuela, ya que es un espacio institucionalizado dependiente del gobierno local. A este respecto, María, en alusión a una apoderada que forma parte de la directiva del centro de padres en su escuela, señala lo siguiente:

De partida por su forma de ser, ella es muy amable, tiene buena comunicación, se nota la relación que tiene con su hija, tiene buena relación con toda la comunidad, tiene un hijo mayor que tiene 22 años, yo no lo conocí, pero fue alumno de la escuela. Además, ella vive atrás de la escuela, está cerca, así que se lo pasa viniendo a la escuela, pertenece a la directiva, es super jugada por la escuela. (María, profesora comuna de Quillón)

A diferencia de María, Carmen destaca, en un contexto de enunciación próximo al fragmento antes citado de su discurso, que, en su experiencia personal, con sus personas apoderadas, la situación es distinta pues reconoce en ellas un alto sentido del compromiso no solo en lo que considera importante (ayuda en las tareas escolares), sino que también en aspectos extracurriculares:

Pero yo en general he encontrado que las apoderadas son comprometidas, a lo mejor no le ayudan mucho en cuanto a lo que es la parte de aprendizaje pedagogía porque no tienen la herramienta como hacerlo... pero sí están atentas a lo que yo les vaya pidiendo, me responden siempre bien. Por ejemplo, para organizar alguna cosa, un baile, decorar la escuela, lo que sea. (Carmen, profesora comuna de Pemuco) 
doi: http://dx.doi.org/10.15359/ree.23-3.4

URL: http://www.una.ac.cr/educare

CORREO: educare@una.cr

Este compromiso no solo está en quienes conforman la directiva, está en todas las personas apoderadas. Carmen pone de manifiesto la importancia que otorga, producto de su propia experiencia como madre a los aspectos afectivos. Experiencia que estuvo marcada por sus condiciones laborales. Debió permanecer distanciada de sus hijas, situación que reconoce afectó su propia vida:

$Y$ yo nunca castigué a una hija, una vez que me quiso levantar la mano, con doce años y sabe que, me dijo, por eso que tiene un costo trabajar lejos de la casa, dejar a la familia me reclamó me lo echó en cara y tú que no estay nunca en la casa. (Carmen, profesora comuna de Pemuco)

Esta experiencia vital ha impulsado, según relata Carmen, prestar atención a aquellos aspectos más vinculados con la dimensión emocional. De este modo se reconoce la activación de otra lógica de acción que no siempre encaja con el modelamiento burocrático del sistema escolar (Dubet, 2010). Al reconocer la falta de herramientas de la mayoría de sus apoderadas para enfrentar las demandas propias de las tareas escolares (en conocimiento y pedagogía), les asigna otro rol. Es un rol más próximo a la posibilidad de proporcionar condiciones socioemocionales que contribuyan a la estabilidad de niños y niñas para, de este modo, contribuir al mejor desempeño de estos.

Le doy harta importancia a que ellos se preocupen más de su hijo. En el sentido que ellos tengan más acercamiento, más demostración de cariño, porque yo he notado aquí ellas mismas me dicen las mamás confiadas, señorita es que yo soy desabría, no estoy acostumbrada a hacerle un cariño. En cambio, yo soy más afectiva, sé que a los niños hay darles harto cariño, ve que cuando yo estaba lejos de la casa mis hijas me lo sacaron en cara. Una vez una mamá de esas que estaban medias lejanas, justo la mamá es poco demostrativa de cariño, llegó aquí, me llamó y me dijo: profesora yo puedo ir a ayudar a vestir a mi hija... excelente le dije yo, porque me tocaba a mi antes hacer todo, y pensé que era bueno para que ella estuviera más cerca de su niña. (Carmen, profesora comuna de Pemuco)

La posibilidad de generar espacios de encuentros entre las familias y la niñez es un espacio que Carmen no desaprovecha, pues le otorga importancia, dada su propia experiencia. En el fragmento se alude a una madre que quiso acompañar a su hija a una competencia de cueca (baile nacional de Chile) que se celebra cada año en la comuna, ella había sido seleccionada para representar a su escuela y la madre quiso ir a apoyarla. Aunque estos espacios responden a espacios extracurriculares, son visualizados como oportunidades de acercamiento que, tal como se indicó anteriormente, redundan en beneficios para el clima en la escuela. 
El reconocimiento de estas oportunidades que se visualizan en el discurso de Carmen, tienen un correlato en el discurso de Rebeca, profesora de una de la escuela de la comuna de Coihueco. La visualización más integral del quehacer docente está mediada por la experiencia en la multiplicidad de mundos vividos por los sujetos agentes (Díaz de Rada, 1996), pues no se alude a la experiencia exclusiva del aula o el desempeño profesional. No se alude a ese rol configurado y modelado desde la escuela como espacio burocratizado (Rockwell, 2009), más bien refiere a un rol múltiple, sobre la base del aprendizaje situado (Lave y Wenger, 2006) donde se activan diversos sistemas de disposiciones para la acción (Lahire, 2004):

Yo creo que la vida a uno le enseña este tejemaneje de conocer a la gente y de entregarme, es que yo me creo como asistente social, psicóloga, un montón de cosas, enfermera es lo único que no he podido lograr porque le tengo un montón de miedo a los cortes y todas esas cosas. (Rebeca, profesora comuna de Coihueco)

El conocimiento acabado del contexto es otro de los elementos que aparece como fuente modeladora de las representaciones sociales que el profesorado tiene respecto de las familias, su rol y la relación que establecen con la escuela. A este respecto, el discurso de Luciano es ilustrativo.

Uno conoce a la gente, sabe cuándo hay problemas ... a veces se ven algunos que tienen alguna cuestión entre familias, pero como uno los conoce sabe cómo calmar los ánimos. Si como yo soy de aquí, siempre he participado aquí en la junta de vecinos, soy el tesorero. No he querido ser presidente porque hay muchas reuniones y uno no tiene tiempo, no puede dejar la escuela sola. También he estado en el comité de agua potable, también como tesorero, me dejan unos años y después me vuelven a llamar. Por eso uno conoce a todos por aquí, uno sabe cuándo alguno no viene a las reuniones de la escuela porque tiene algún problema, pero también sabe altiro (inmediatamente) cuando no vienen porque no están ni ahí con venir. (Luciano, profesor comuna de Quillón)

Nuevamente, la asistencia a reuniones programadas por la escuela aparece como elemento central para determinar el grado de compromiso e involucramiento de las familias. De este modo, persiste una valoración sobre la base de la lógica de presencia-ausencia, pero esta vez respaldada por el conocimiento del entorno cultural y familiar. Es este conocimiento el que proporciona argumentos para clasificar a las familias. En consecuencia, el binomio presencia-ausencia es otro de los elementos que configuran el núcleo de la representación que el profesorado tiene respecto de la relación familia-escuela.

La relevancia del contexto como elemento modelador de las representaciones del compromiso de las familias y el rol que estas cumplen en el proceso de escolarización de niños y niñas se aprecia también en el discurso de Cristóbal. Plantea que mientras mejor sea el 
doi: http://dx.doi.org/10.15359/ree.23-3.4

URL: http://www.una.ac.cr/educare

CORREO: educare@una.cr

conocimiento del contexto en el cual está inserta la escuela, en términos familiares, relaciones de parentesco, capital social, capital cultural, etcétera, más significativo es el apoyo que puede conseguir el docente para sacar adelante los objetivos.

Cuando llegué a la escuela me vinieron literalmente a tirar aquí no más. Me dijeron que había un lugar para dormir y ya está. No tenía luz eléctrica así que un poco a tientas tuve que acomodar mis cosas. Con el tiempo las cosas fueron mejorando, conocí mejor a la gente y el profesor encargado que estaba se fue, así que me quedé solo hasta ahora. En general uno cuenta con el apoyo de las mamás y los papás, se comprometen con todo, especialmente cuando se trata de desmalezar, hacer cercos, juntar leña y también cuando hay que defender la escuela para que no la cierren. Las familias apoyan porque ven que sus hijos aprenden, de hecho, nosotros hemos obtenido la excelencia académica un par de años, eso ayuda a que las familias se involucren. (Cristóbal, profesor comuna de Quillón)

Como se aprecia en el fragmento recientemente expuesto, Cristóbal no centra la atención en la asistencia a reuniones, sino más bien en el cumplimiento de roles específicos de las familias. El profesor destaca la participación (compromiso) en ámbitos extraacadémicos, pero que cobran sentido para él en la medida que los fundamenta desde la consecución de logros académicos. De este modo, el apoyo en la limpieza, mantención de cercos y recolección de leña, aunque no corresponden a apoyos de carácter académico, según Cristóbal, se fundan en la valoración positiva que las familias realizan al profesor y la escuela por el reconocimiento a la excelencia académica otorgada por el Ministerio de Educación de Chile.

Por otra parte, Alberto plantea que las propias vivencias son fundamentales a la hora de abordar la temática del compromiso familiar en el desempeño escolar de niños y niñas.

A este respecto indica:

Yo estaba en otra escuela, pero por otros temas el alcalde decidió cambiarme de escuela. En mi otra escuela yo tenía hartos alumnos, teníamos un buen trabajo ahí, con toda la comunidad, pero tuvimos unos problemas al parecer y el alcalde me envió a esta escuela. Aquí la escuela estaba para cerrarse, había apenas cuatro niños. Al comienzo fue complicado, porque los niños no hacían caso a nadie. Recordando ese primer período, lo que hice fue probar con las cosas que hice en la otra escuela, cambiando algunas cosas porque el sector es otro y con otras problemáticas. Yo creo que las familias del sector se dieron cuenta de esto y poco a poco se fueron haciendo más partícipes de la escuela y de las cosas que yo necesitaba para sus niños. Tan bueno fue esto que en un año pasamos de cuatro niños a nueve. (Pedro, profesor comuna de Pemuco) 
En el relato de Alberto se aprecia cómo la experiencia vivida proporciona herramientas para enfrentar una situación inicialmente dificultosa. Herramientas que se activan al modo de resortes para la acción, tal como lo señala Lahire (2004). Pero más allá de los resortes para la acción, lo que se desprende del relato de Alberto cobra gran valor analítico toda vez que da cuenta de que las prácticas cotidianas se reactivan evocativamente, aunque sin plena consciencia. Cobran consciencia en la medida que se invita al profesorado a retomar dicha experiencia en un contexto de interlocución. Tal como indica Lahire (2004): "se toma conciencia de que la evidencia del mundo y de la mayoría de los actos prácticos en la vida cotidiana supone una especie de ajuste no consciente de un cuerpo socializado a situaciones sociales" (p. 176). Así, en el contexto de entrevista, Alberto reconoce en esas experiencias pasadas la base para la implicación de las familias en la escuela en la que actualmente se desempeña.

Finalmente, en los casos de Luciano, Cristóbal y Alberto se reconoce lo expuesto por Dubet (2010):

[El profesorado no habla] de su rol, sino de su experiencia, pues dedican lo esencial de sus palabras a decir que no son personajes y que se constituyen como individuos desde la distancia respecto a su rol y no por su total adhesión. (p. 88)

\section{Representaciones sociales sobre la relación familia-escuela desde la visión de las familias}

La asistencia a la escuela por parte de la personas apoderadas se da fundamentalmente en tres instancias: reuniones mensuales, las 'convivencias' (celebraciones) y trabajos voluntarios. En casos excepcionales padres y madres solicitan entrevistas individuales. La evidencia reconoce estas instancias como espacios de participación y reflejo del compromiso de las familias con el proceso de escolarización de los niños y las niñas (Cárcamo-Vásquez y Rodríguez-Garcés, 2015; Colás y Contreras, 2013).

La representación que las familias poseen respecto a su relación con la escuela se cimienta en los aspectos enunciados en el párrafo precedente. Se reconoce con una clara regularidad discursiva. No obstante, es posible constatar que la experiencia familiar, en cuanto a etapa del ciclo vital, número de hijos o hijas, experiencia previa como apoderado, establece una diferencia al momento de modelar la representación que poseen de la escuela y la relación que establecen con esta. Muestra de ello lo encontramos en el discurso de Marisol.

Yo tengo otro hijo mayor que pasó por esta misma escuela, ahora estamos con algunos problemas porque se ha farreado tres años, empezó estudiando en un instituto, dos años estuvo ahí y los perdió. Ahora está en la universidad y también está complicado. Nosotros 
doi: http://dx.doi.org/10.15359/ree.23-3.4

URL: http://www.una.ac.cr/educare

CORREO: educare@una.cr

nos preocupamos de él cuando estaba chico y lo seguimos haciendo, pero el papá ya quiere que se dedique a ayudarle en el campo. Yo quiero que siga estudiando, ¿qué ejemplo va a ser para el chico? Yo ahora, cuando no sé algo voy y le pregunto a la profesora, siempre fui a las reuniones, pero ahora pregunto más para que no nos vaya a pasar lo mismo que con el otro hijo. (Marisol, apoderada comuna Coihueco)

La experiencia con el hijo mayor se constituye, en el caso de Marisol, en el eje de significación más relevante para definir su relación con la escuela y desde la cual fundamenta la necesidad de establecer un vínculo más estrecho con el acontecer institucional. Aunque reconoce las debilidades propias en materia educacional con frases como: "solo llegué a séptimo", "las formas de enseñar las matemáticas han cambiado", "hay cosas que no entiendo", estas en la actualidad no resultan ser un obstáculo para involucrarse en el proceso de escolarización de su hijo menor, a diferencia de su experiencia previa, donde se apoyaba en cuestiones extracurriculares, como por ejemplo trabajo voluntario de mantención de la escuela y decoración del espacio para determinadas festividades. Tal como ella señala: "ahora pregunto más".

En una línea similar encontramos a Fresia, quien es apoderada de su nieto (alumno de $4^{\circ}$ año básico). Ella señala que actualmente ocupa un cargo en la directiva del centro de padres, madres y personas apoderadas de la escuela por considerar que desde allí puede apoyar de mejor forma en aquellas dimensiones que estima son importantes para el desarrollo de la vida escolar de la niñez. Específicamente, otorga un valor fundamental a la relación de las familias con la escuela, el compromiso desde un punto de vista operativo.

En la directiva nos preocupamos de tener todas las cositas que necesitan los niños, nos preocupamos de hacer actividades para juntar platita para un regalito de fin de año, para un paseo, pero también para otras cosas que son como inesperadas como una ampolleta quemada, un escobillón que falte ... lo que sea y que podamos lo compramos. En la directiva hacemos el plato único, el otro día hicimos uno y nos fue harto bien. Eso lo planificamos al inicio de cada año, hacemos dos o tres platos únicos porque nos va 're bien.' Siempre contamos con la ayuda de algunas mamitas para cocinar, otros que no pueden mandan su cooperación. Así van saliendo las cosas. (Fresia, apoderada comuna de Quillón)

El aspecto operativo al que se alude en el párrafo precedente se visualiza, con toda claridad, en frases como las siguientes: "si se quema una ampolleta, vamos y la cambiamos", "si falta un escobillón, lo compramos", "si falta un cargador para un computador de la profesora, lo compramos". Fresia pone de manifiesto que las familias pueden y deben involucrarse en este aspecto. pues va en directo beneficio del alumnado de cada escuela. La forma de obtener los recursos por parte de la directiva del centro de padres, madres y personas apoderadas de este establecimiento educacional adquiere dos vías. Por una parte "el plato único", que consiste en la 
preparación de un almuerzo para las personas de la comunidad, almuerzo que tiene por objetivo generar recursos económicos y un espacio de convivencia; pero, en caso de no ser posible la asistencia, también puede ser llevado para la casa de quienes hayan pagado su adhesión. Es una actividad que reporta importantes ingresos. Otra vía son las donaciones tanto de las propias familias cuyos hijos o hijas asisten a la escuela, como por otras personas de la localidad.

Fresia tuvo a sus hijos e hijas (4) en la escuela, hoy decide asumir la tutela del nieto, pues la madre del niño (hija de Fresia) y su esposo tienen trabajo fuera de la comuna. Su experiencia es reconocida tanto por el profesorado como por las demás personas apoderadas que insisten en que sea parte de la directiva del centro por ser conocedora de las necesidades que tiene la comunidad educativa.

Si son los mismos apoderados los que me piden que esté en el centro general de padres, yo no quería porque quería estar pendiente de mi nieto, porque quiero que le vaya bien en la escuela, pero también pienso que tengo que ayudar en las otras cosas que son importantes porque, aunque no tengo mucha educación sí sé cómo ayudar pa' que la escuela funcione mejor. (Fresia, apoderada comuna de Quillón)

Por otra parte, entre los discursos aparece como fuente de la variante discursiva el ciclo vital de la familia, expresado en la escasa experiencia de las entrevistadas del rol de apoderadas. En estos casos, se aprecia una representación del rol y vínculo con la escuela más centrado en aspectos de gestión del aula. Son las madres quienes asumen el rol de apoderada por primera vez, las que expresan una mayor preocupación por la educación de su progenie.

En el caso de Mercedes, su única hija cursa el primer año básico. El nivel inicial al que asiste su hija podría explicar la preocupación principal de esta madre en aspectos relativos el desempeño de su hija al interior del aula. Tal como lo señala Enkvist (2011), la preocupación de los padres y madres por el desempeño de sus hijos e hijas, así como el involucramiento en actividades académicas propias de la escuela se evidencia principalmente en los primeros años de escolarización y a medida que avanza el proceso educativo esta comienza a distanciarse. Mercedes comenta lo siguiente:

Yo vengo a buscar mi hija, vengo a saber cómo se ha portado en clases, a eso más que nada. No me meto en más cosas, a no ser que el profesor le pida a uno alguna ayuda o alguna cooperación. Pero vengo más que nada a saber cómo está mi hija. En las reuniones escucho no más para saber cómo va el curso y después cuando la reunión termina le pregunto al profe por la niña. (Mercedes, apoderada comuna de Pemuco) 
doi: http://dx.doi.org/10.15359/ree.23-3.4

URL: http://www.una.ac.cr/educare

CORREO: educare@una.cr

Por su parte, Teresa, apoderada cuyo único hijo cursa primer año básico, expone que en general la relación de las familias con la escuela está modelada y determinada por las demandas específicas de la escuela. Sostiene que las personas apoderadas responden a solicitudes del profesorado encargado de la escuela, reconociendo una actitud pasiva por parte de madres y padres. Al respecto, señala lo siguiente:

Los apoderados han venido, pero como en dos ocasiones a ayudar con el patio de la escuela. También a pintar vinieron los apoderados. Pero en general no es que sean ellos que se reúnan y organicen para decir vamos a ser esto o lo otro; no, eso es cuando el profesor hace algo y pide la ayuda así llegan los apoderados, pero no es que los apoderados quieran organizar algo ellos por su cuenta. Yo por ejemplo estoy calladita nos más, no me ofrezco para nada, pero igual vengo a ayudar en todo, aunque no me haya comprometido. Así el profesor me ve y me quedo conforme porque sé que eso le ayuda a mi hijo, después cualquier duda que yo tenga se la puedo preguntar al profesor y él siempre tiene la voluntad y se hace el tiempo para mí. (Teresa, apoderada comuna de Quillón)

En el relato de Teresa se aprecia lo que en otras ocasiones se ha visualizado: la relación que la familia establece con la escuela está mediada esencialmente por demandas específicas de la escuela. Además, se reproduce un tipo de demanda en particular, relacionada con la satisfacción de necesidades específicas, de carácter material: mantención de los cercos perimetrales, renovación de pintura del establecimiento educacional, arreglos menores (piso, techumbre), entre otros. Sin embargo, se reconoce en el relato una acción con arreglo a fines; Teresa aporta, ayuda, coopera, poniendo de manifiesto su estrategia. Considera que, al responder a las solicitudes del profesorado, obtiene beneficios que contribuyen directamente en lo que realmente le interesa: el desempeño escolar de su único hijo.

Lo expuesto en este apartado permite reconocer que el núcleo de la representación que padres, madres y personas apoderadas poseen respecto de la relación familia-escuela, está dado por una lógica de subordinación a las demandas de la escuela. Ya sea para la colaboración en el ámbito académico (generación de hábitos de estudio, cumplimiento de tareas escolares, envío de material para el trabajo en aula, etcétera), o para la colaboración en el mantenimiento del establecimiento educacional y el desarrollo de actividades recreativas de tipo curricular o extra programáticas.

\section{Conclusiones}

Tras el análisis del corpus discursivo, se ha constatado que la experiencia posee una influencia significativa como fuente modeladora de las representaciones que el profesorado y las familias construyen de la relación familia-escuela y de los roles que atribuyen a uno u otro agente en el proceso educativo.

\begin{tabular}{l|l}
\hline 16 & Héctor Cárcamo-Vásquez y Pablo Méndez-Bustos
\end{tabular}

Los artículos de la Revista Electrónica Educare del Centro de Investigación y Docencia en Educación de la Universidad Nacional, Costa Rica, se comparten bajo términos de la Licencia Creative Commons: Reconocimiento, № Comercial, Sin Obra Derivada 3.0 Costa Rica. Las autorizaciones adicionales a las aquí delimitadas se pueden obtener en el correo: educare@una.cr 
De acuerdo con el trabajo desarrollado, se puede concluir la existencia manifiesta de espacios múltiples para la construcción de la experiencia docente. ¿Cuáles son estos? De acuerdo con el análisis desarrollado, se identifican principalmente tres espacios fundamentales: el primero de estos alude a la propia carrera docente, operacionalizada a través de años de experiencia en aula; el segundo, se corresponde con el conocimiento del contexto en el cual está inserta la escuela, conocimiento del contexto que se torna relevante en aquellos sujetos que habitan en la comunidad y, por tanto, son parte de esta misma; y, el tercero, relacionado con la propia experiencia como persona apoderada, rol que, aunque se desarrolla en el espacio público (campo escolar), adquiere un carácter privado -en el marco de enunciación de la entrevista- en la medida que alude a la relación filial que establece el sujeto con sus propios hijos o hijas.

Otro aspecto relevante en el análisis se relaciona con la utilización de un eje de carácter temporal como base para la configuración de las representaciones que poseen respecto a las familias. El eje temporal permite elaborar valoraciones sobre el compromiso ante el cumplimiento del rol parental educativo que el profesorado asigna a las familias. De este modo se devela una clara regularidad discursiva a partir de la cual se atribuye una valoración positiva de las familias de antaño, pues se estima que estas demostraban mayor compromiso con la escuela y la niñez. ¿Cómo se sustenta desde el discurso del profesorado esta valoración? Se alude a cuestiones formales como: la asistencia a reuniones, la asistencia a las entrevistas individuales, la participación acciones de voluntariado. Por su parte, en la actualidad se aprecia una valoración disminuida en términos comparados, pues las familias actuales demuestran un menor compromiso con el rol parental educativo (que el propio profesorado asigna a las familias), nuevamente cabe preguntarse ¿en qué se sustenta dicha valoración negativa o desmejorada? De igual forma, aspectos formales derivados de una lógica unidireccional, vertical y descendente: asistir a reuniones fijadas por el profesorado, asistir a las entrevistas individuales para dar indicaciones orientadas a la mejora del desempeño escolar del niño o niña, cooperar con trabajo para mantención de cercos, renovación de pintura, limpieza, entre otros.

Por su parte, desde la concepción de las familias, ha sido posible reconocer el peso de la experiencia producto del momento del ciclo vital en el que se encuentran los sujetos entrevistados. De este modo, quienes poseen experiencias previas como personas apoderadas refieren a una representación del rol en materia educativa y la relación que las familias establecen con la escuela centrado en apoyos extracurriculares, atendiendo a necesidades emanadas desde el profesorado, en temas como: limpieza, pintura, reposición de insumos menores, entre otros. Asimismo, aquellas familias cuya experiencia como apoderada recién comienza con su primer y único hijo o hija dan cuenta de una representación anclada en su propia necesidad de saber cómo va desarrollándose su experiencia escolar. Se ve, en este sentido, la activación de recursos específicos para la acción. Estos recursos operan a modo de estrategias para lograr conciliar aparentemente diversas lógicas de acción con sistemas que se superponen mediante espacios liminares. 
doi: http://dx.doi.org/10.15359/ree.23-3.4

URL: http://www.una.ac.cr/educare

CORREO: educare@una.cr

De este modo, el peso de la experiencia como modeladora de las representaciones que profesorado y familias poseen respecto de la relación familia-escuela y el rol que a cada sujeto le compete, está dado por la confluencia de los múltiples mundos vividos por los sujetos agentes interpelados. En consecuencia, es posible reconocer que el núcleo central que configura la representación respecto de la relación familia-escuela varía según el tipo de agente. En el caso del profesorado, el núcleo está constituido por una lógica escolar centrada que activa valoraciones respecto del compromiso de las familias sobre la base de del binomio presencia-ausencia. En el caso de las familias, el núcleo central que configura la representación respecto de la relación familia-escuela está dado por una lógica de subordinación a las demandas específicas que emanan de la escuela.

Los hallazgos expuestos ponen de manifiesto la necesidad de abordar la temática de la relación familia-escuela en los contextos escolares, como un fenómeno que no solo contribuye a la mejora de los rendimientos académicos de niños y niñas, sino que también aporta en la configuración de espacios dialógicos que facilitan la problematización de la realidad, una mejor gobernanza escolar y el desarrollo de una cultura democrática efectiva. En tal sentido, se torna relevante la generación y promoción de momentos, espacios e instancias de encuentro entre los diversos sujetos agentes que constituyen las comunidades educativas para promover una relación familia-escuela sustentada en canales de comunicación bidireccionales fluidos, espacios y estructuras de participación (individual y colectiva) más allá del nivel informativo y una implicación en el quehacer de la escuela que trascienda los intereses individuales.

Finalmente, tras el desarrollo de la investigación, se aprecia el peso que la experiencia adquiere en el análisis de las trayectorias de los sujetos y los respectivos roles que asumen en contextos tan específicos como el campo de lo escolar. Asumiendo que el devenir de los sujetos se moviliza sobre la base de la activación simultánea de diversas lógicas de acción, en este trabajo hemos procurado prestar atención a los diversos pliegues constitutivos de lo social.

\section{Agradecimiento}

Este artículo se desprende de los proyectos de investigación Fondecyt N. ${ }^{\circ} 11160084$, CONICYT y DIUBB 161224 3/R Dirección de Investigación Universidad del Bío-Bío.

\section{Referencias}

Abric, J.-C. (2001). Las representaciones sociales: Aspectos teóricos. En J.-C. Abric (Direc.), Prácticas sociales y representaciones (pp. 11-32). México: Coayacán.

Bourdieu, P. y Passeron, J. (1979). La reproducción. Elementos para una teoría del sistema de enseñanza. Barcelona: Laia. 
Calvo, M. I., Verdugo, M. Á. y Amor, A. M. (2016). La participación familiar es un requisito imprescindible para una escuela inclusiva. Revista Latinoamericana de Educación Inclusiva, 10(1), 99-113. doi: https://doi.org/10.4067/S0718-73782016000100006

Cárcamo-Vásquez, H. (2015). Ciudadanía y educación. Imágenes sobre la formación para la ciudadanía en la escuela y sus procesos de configuración. Concepción, Chile: UBB.

Cárcamo-Vásquez, H. (2016). Microcentros de escuelas rurales de la provincia de Ñuble, Chile: Representaciones que posee el profesorado respecto a de su impacto en el quehacer pedagógico en el escenario de la nueva ruralidad. Sinéctica, 47, 1-17. Recuperado de http://www.scielo.org.mx/pdf/sine/n47/2007-7033-sine-47-00010.pdf

Cárcamo-Vásquez y Rodríguez-Garcés, C. (2015). Rol parental educativo: Aproximación a las percepciones que poseen los futuros profesores. Educación y Educadores, 18(3), 456-470. doi: https://doi.org/10.5294/edu.2015.18.3.5

Chinchilla, R. y Jiménez, F. (2015). Necesidades de orientación de padres y madres de colegios académicos diurnos de la Dirección Regional de San José. Actualidades Investigativas en Educación, 15(1), 1-25. doi: https://doi.org/10.15517/aie.v15i1.17630

Colás, P. y Contreras, J. A. (2013). La participación de las familias en los centros de educación primaria. Revista de Investigación Educativa, 31(2), 485-499. doi: https://doi.org/10.6018/ rie.31.2.171031

Cuevas. Y. (2012). Apuntes sobre la teoría de representaciones sociales. En R. C. Flores (Coord.), En la búsqueda de los sentidos y significados de la educación ambiental (pp. 21-44). México: Universidad Pedagógica Nacional.

Díaz de Rada, A. (1996). Los primeros de la clase y los últimos románticos. Una etnografía para la crítica de la visión instrumental de la enseñanza. Madrid: Siglo XXI.

Dubet, F. (2010). Sociología de la experiencia. Madrid: Complutense.

Enkvist, I. (2011). La buena y la mala educación. Ejemplos internacionales. Madrid: Encuentro.

Fawaz, M. J. (2015). Una mirada analítica de la provincia de Ñuble desde el sector rural, la mujer y la familia. En B. Umaña (Ed.), Caracterización de la provincia de Ñuble y una propuesta estratégica para el desarrollo del territorio (pp. 181-276). Concepción: UBB.

Jodelet, D. (1986). La representación social: Fenómeno. Concepto y teoría. En S. Moscovici (Comp.), Psicología Social, II. Pensamiento y vida social (pp. 478-494). Barcelona: Paidós.

Lacolla, L. (2015). Representaciones sociales de los estudiantes acerca de las reacciones químicas. En R. Calixto (Coord.), Representaciones sociales en la práctica educativa y en la formación docente (pp.19-34). México: ISCEEM. 
Lahire, B. (2004). El hombre plural. Los resortes de la acción. Barcelona: Bellaterra.

Lave, J. y Wenger, E. (2006). Situated Learning. Legitimate peripherical participation. New York: Cambridge University Press.

Moscovici, S. (1979). El psicoanálisis, su imagen y su público. Buenos Aires: Huemul.

Muñoz, C., Ajagan, L., Sáez, G., Cea, R. y Luengo, H. (2013). Relaciones dialécticas antagónicas entre la cultura escolar y la cultura familiar de niños y niñas de contextos vulnerables. Universum, 1(28), 129-148. doi: https://doi.org/10.4067/S0718-23762013000100007

Páez, R. M. (2015). Familia y escuela: Una alianza necesaria en la gestión escolar. Revista Iberoamericana de Educación, 67, 159-180. Recuperado de https://rieoei.org/RIE/article/ view/228

Ramírez-Miranda, C. (2014). Critical reflections on the New Rurality and the rural territorial development approaches en Latin America. Agronomía Colombiana, 32(1), 122-129. doi: https://doi.org/10.15446/agron.colomb.v32n1.41218

Rockwell, E. (2009). La experiencia etnográfica. Historia y cultura en los procesos educativos. Buenos Aires: Paidós.

Schilling, C. (2015). La construcción de nuevas interacciones entre familia y escuela: Avanzando hacia una perspectiva comunicativa del espacio escolar. En V. Nogués y A. Precht (Eds.), Nuevas formas de relación en la escuela: Reflexionar y transformar (pp. 195-214). Santiago: Ediciones Universidad Santo Tomás.

Vera, D., Osses, S. y Schiefelbein, E. (2012). Las creencias de los profesores rurales: Una tarea pendiente para la investigación educativa. Estudios Pedagógicos, 38(1), 297-310. doi: https://doi.org/10.4067/S0718-07052012000100018 